\title{
Analysis of traffic-related air pollution using Shanghai road traffic state index
}

\author{
Ruoyu Chen ${ }^{1, *}$, Lianliang Chen ${ }^{2}$, and Wenhao Fan ${ }^{1}$ \\ ${ }^{1}$ School of Software Engineering, University of Science and Technology of China, 215123, Suzhou, \\ China \\ ${ }^{2}$ College of Information Engineering, Northwest A\&F University, 712100, Yangling, China
}

\begin{abstract}
Recently, due to the rapid economic development and the acceleration of urbanization, haze events have occurred frequently in most parts of China, which has attracted widespread attention at home and abroad. This study presents a statistical summary of air pollution concentrations and traffic state indexes from August 2014 to April 2015 in Shanghai, China. We find $\mathrm{PM}_{2.5}$ concentrations show a remarkable seasonal variability with "winter $>$ spring $>$ autumn $>$ summer" in Shanghai. Concentrations of $\mathrm{PM}_{2.5}, \mathrm{CO}, \mathrm{NO}_{2}, \mathrm{SO}_{2}$ are generally higher in winter than in summer due to enhanced anthropogenic and biogenic emissions and unsuitable meteorological conditions for pollution diffusion, contrary to concentrations of $\mathrm{O}_{3}$. The weekly changes of $\mathrm{NO}_{2}$ are highly consistent with that of traffic state indexes, suggesting a significant contribution to $\mathrm{NO}_{2}$ concentrations from road traffic emissions. Two moderate peaks are found in the diurnal variability of concentrations of $\mathrm{PM}_{2.5}, \mathrm{CO}$ and $\mathrm{NO}_{2}$, similar to road traffic indexes, indicating the important contribution of road traffic emissions every day. We find that $\mathrm{SO}_{2}, \mathrm{NO}_{2}, \mathrm{CO}$ are the dominant factors contributing to $\mathrm{PM}_{2.5}$ pollution, where $\mathrm{NO}_{2}$ and $\mathrm{CO}$ are mainly from road traffic emissions. The average annual Spearman correlation coefficient is $\mathrm{r}=0.689(\mathrm{p}<0.01), \mathrm{r}=0.564$ $(\mathrm{p}<0.01), \mathrm{r}=0.812(\mathrm{p}<0.01)$, respectively.
\end{abstract}

\section{Introduction}

With the rapid urbanization and the continuous increase in the number of vehicles, road traffic emissions have become a major source of air pollutant in urban areas. Atmospheric pollutants emitted by road traffic, such as carbon monoxide $(\mathrm{CO})$, nitrogen oxides $\left(\mathrm{NO}_{\mathrm{x}}\right)$ and non-methane hydrocarbon (THC), have caused adverse environmental pollution, particularly in areas near major roads. Vehicle emissions have become an important source of urban air pollution throughout the world[1].

Particulate matter (PM) is widely regarded as a major factor, which causes degrading visibility and a significant impact on human health, attracting a lot of attention from researchers at home and abroad. Yanlin Zhang et al. [2] present a significant spatial and seasonal distribution of $\mathrm{PM}_{2.5}$ pollution in China. Lijian Han et al. [3] find that intensive

\footnotetext{
* Corresponding author: chenry@mail.ustc.edu.cn
} 
human activities play an important role in urban air pollution. Kendrick et al. [4] suggest that roadside $\mathrm{PM}_{2.5}$ is more dependent on regional sources and meteorological conditions. However, traffic state indexes are rarely used to analyze the relationship between traffic and $\mathrm{PM}_{2.5}$ pollution due to lack of real-time monitoring. Furthermore, a macro perspective at a city level is also needed to analyze the contribution of road traffic in the air pollution.

\section{Datasets}

We use the following two real datasets, where all sources are available from August 1st, 2014 to April 30th, 2015 in Shanghai, China.

1)Air quality records: We collect real-valued air quality indexes (AQI) of four kinds of air pollutants, including $\mathrm{PM}_{2.5}, \mathrm{SO}_{2}, \mathrm{NO}_{2}$ and $\mathrm{O}_{3}$, recorded by ground-based air quality monitor stations in Shanghai every hour. Data are obtained from the National urban air quality in real time publishing platform of China National Environmental Monitoring Centre.

2)Traffic state indexes: Ground road traffic state indexes are obtained from Shanghai Open Data Apps (SODA), 2015. Data are provided by the Shanghai Municipal Transportation Commission.

Traffic State Index (TSI) is a macro indicator for evaluating the overall operational status of urban transport and is widely used in the formulation of relevant policies on major cities such as Beijing, Shanghai and Guangzhou. In this paper, road traffic indexes are generated in real time by Shanghai Comprehensive Transport Information Platform every 2 minutes and can be seen as assessment indicators for quantifying traffic congestion[5]. The basic calculation of road traffic indexes is shown as follows

$$
\mathrm{TSI}=\frac{v_{f}-v_{i}}{v_{f}} \times 100
$$

where $v_{i}$ denotes average travel speed of vehicles in road section $i$, and $v_{f}$ denotes free flow speed of the road section $f$. The value of road traffic indexes is between 0 and 100 . The greater the value is, the more crowded the road is.

In this paper, road traffic indexes are used to indicate road traffic conditions and analysis traffic-related air pollution in Shanghai. Note that our research is based on a macro perspective at a city level, so data collected from all monitor stations are averaged per hour to get an overall evaluation in urban Shanghai.

\section{Experiments}

\subsection{Seasonal variation of air pollution and TSI in Shanghai}

In this study, we divide our data into four seasons by using pentad temperature method. Figure 1(b) illustrates the seasonal variation of $\mathrm{PM}_{2.5}$ concentrations in Shanghai. Generally, $\mathrm{PM}_{2.5}$ concentrations show a remarkable seasonal variability with "winter $>$ spring $>$ autumn > summer" in Shanghai. $\mathrm{PM}_{2.5}$ is much increased during the winter associated with the enhanced anthropogenic and biogenic emissions and unsuitable meteorological conditions for pollution diffusion, while stagnant weather and temperature inversion occur more frequently in cold weather. The summertime minimum is associated with the reduced anthropogenic emissions such as biomass and biofuel burning for heating. Furthermore, we find relatively high $\mathrm{PM}_{2.5}$ concentrations in the agricultural harvest season of autumn, 
which may be related to increased open biomass burning (i.e. agricultural waste burning) in Shanghai and its surrounding areas.

However, as depicted in figure 1(a), seasonal variability of traffic state indexes is not obvious, except for the wee hours of the morning between 0:00 and 6:00 am, with the highest in summer and the lowest in winter. This may be because of the cool weather after midnight, which is more suitable for human activities in summer.

As figure 1(b) shows, concentrations of $\mathrm{PM}_{2.5}, \mathrm{CO}, \mathrm{NO}_{2}, \mathrm{SO}_{2}$ all show a significant seasonal variability with the highest in winter and the lowest in summer, contrary to concentrations of $\mathrm{O}_{3}$. This may be because of relatively high temperature and ultraviolet intensity in summer, which is more suitable for the formation of $\mathrm{O}_{3}$.

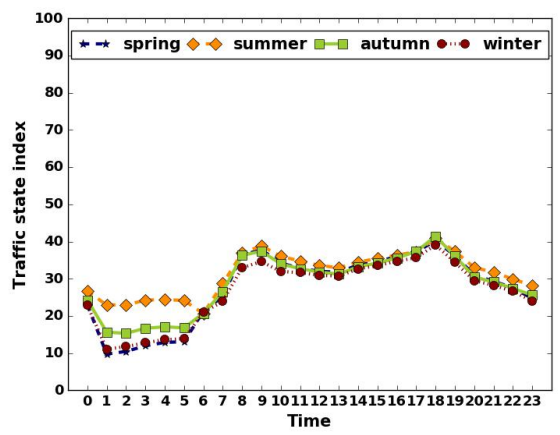

(a) Traffic state indexes

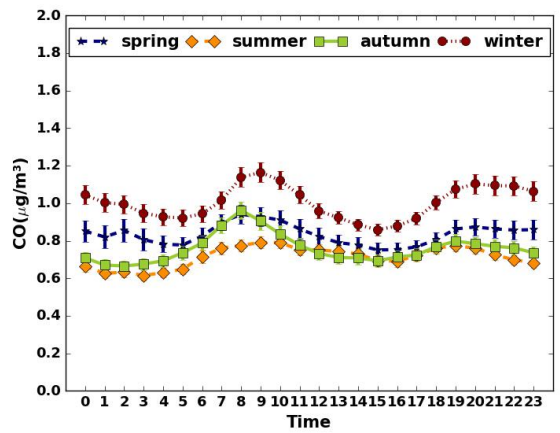

(c) $\mathrm{CO}$

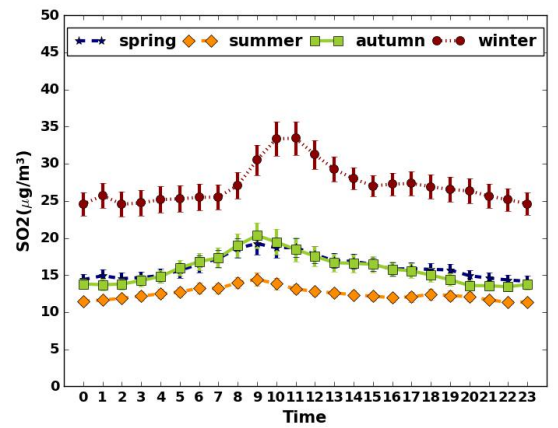

(e) $\mathrm{SO}_{2}$

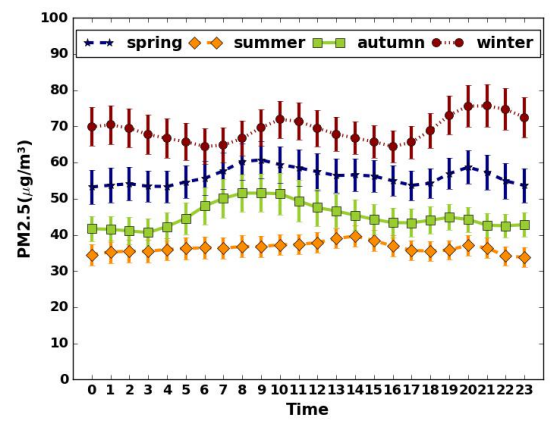

(b) $\mathrm{PM}_{2.5}$

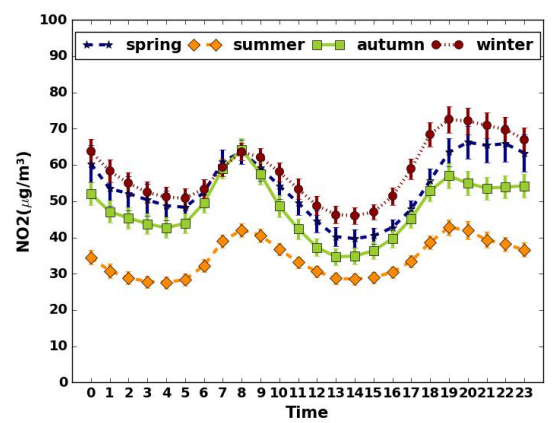

(d) $\mathrm{NO}_{2}$

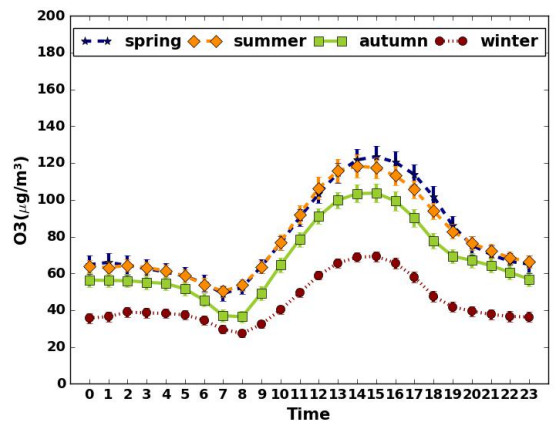

(f) $\mathrm{O}_{3}$

Fig. 1. Diurnal variations of diurnal air pollution concentrations and TSI in Shanghai.

The difference between $\mathrm{PM}_{2.5}$ concentration and traffic state indexes in seasonal variation indicates that the $\mathrm{PM}_{2.5}$ concentrations in Shanghai are not only affected by road 
traffic emissions but also by other factors such as meteorological conditions and secondary aerosol.

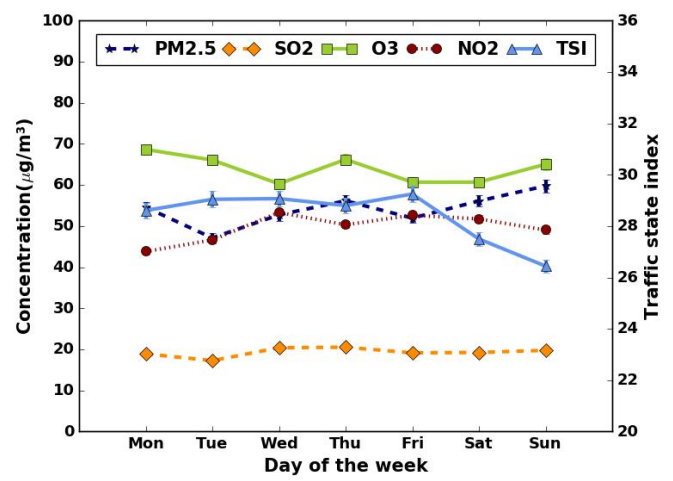

Fig. 2. Weekly variations of diurnal air pollution concentrations and TSI in Shanghai.

\subsection{Weekly variation of air pollution and TSI}

Figure 2 illustrates the weekly variation of diurnal air pollution concentrations and TSI in Shanghai, China. Notice that concentration of $\mathrm{CO}_{2}$ is relatively lower as compared to other pollutions (Figure 1(c)), it is not shown in this figure. Generally, $\mathrm{PM}_{2.5}$ concentrations show a significant weekly variability with "Sunday $>$ Saturday $\approx$ Thursday $>$ Monday $>$ Wednesday $>$ Friday $>$ Tuesday" in Shanghai. There is a remarkable difference between weekends and workdays. This atmospheric phenomenon circulates on a weekly scale, known as the weekend effect[6]. Among main sources of $\mathrm{PM}_{2.5}$ pollution, anthropogenic and biogenic emissions (i.e. from power plants and open biomass burning) are relatively stable, with little changes during workdays. Human activities on weekends, such as tourism and barbecue activities, have enhanced particulate emissions in Shanghai, which could also be affected by meteorological conditions and site location of air quality monitor stations.

In figure 2, we could find the weekly variation of $\mathrm{NO}_{2}$ is highly consistent with that of traffic state indexes. This means a significant contribution of road traffic emissions in concentrations of $\mathrm{NO}_{2}$, which is one of the direct products of vehicle emissions. In addition, we could find the weekly variation of diurnal $\mathrm{O}_{3}$ exhibits a reverse trend with that of $\mathrm{NO}_{2}$ and of TSI, which could also be found in diurnal variations, as mentioned in the next subsection. The difference of the weekly variation between $\mathrm{PM}_{2.5}$ concentrations and traffic state indexes shows that the $\mathrm{PM}_{2.5}$ concentrations in Shanghai are affected by a variety of complex physical and chemical interactions among air pollutants (i.e. $\mathrm{SO}_{2}, \mathrm{NO}_{2}$ and $\mathrm{O}_{3}$ ) and various external conditions (i.e. meteorological conditions).

\subsection{Diurnal variation of air pollution and TSI}

We use hourly data to investigate the diurnal variability in air pollutants as well as traffic state indexes. Figure 1(b) shows the diurnal variation of hourly $\mathrm{PM}_{2.5}$ concentrations in different seasons in Shanghai, China. As mentioned above, the concentration of $\mathrm{PM}_{2.5}$ in winter is higher than that in other seasons, and this could be interpreted by the increased anthropogenic and biogenic emissions. Furthermore, affected by East Asian monsoon climate, the heavily polluted air flow is frequently emitted from northwestern sources, including Hebei, Shandong, Anhui and Jiangsu, to Shanghai in winter and spring, contributing much to the air pollution concentration in Shanghai[7]. As figure 1(d) and 1(e) 
shows, the increase of $\mathrm{SO}_{2}$ concentration during the winter is relatively higher than that of $\mathrm{NO}_{2}$, indicating a significant contribution of coal combustion emissions.

We could find two moderate peaks of $\mathrm{PM}_{2.5}$ concentrations: one between 7:30 and 10:30 am, and the other between 7:00 and 9:30 pm. Compared with figure 1(a), this may be related to road traffic peaks, which occurs at rush hours (7:30 to 9:30 am in the morning and 5:00 to 7:00 pm in the evening) in Shanghai. The delay of $\mathrm{PM}_{2.5}$ peaks compared to road traffic peaks could be explained by the relatively long distances between urban crowded roads and air quality monitor stations in Shanghai[8]. Similar peaks could also be found for $\mathrm{NO}_{2}$ and $\mathrm{CO}$, which could be recognized as a tracer for road traffic emissions, indicating the important contribution of traffic-related emissions. In addition, a similar peak in the morning is also seen for $\mathrm{SO}_{2}$, indicating an unignored contribution of coal combustion emissions to daytime $\mathrm{PM}_{2.5}$.

As figure 1(f) shows, the diurnal variation of $\mathrm{O}_{3}$ presents a typical characteristic of only a single peak at around 3:00 pm. Combined with figure 1(d), we could find the diurnal variation of $\mathrm{O}_{3}$ exhibits a reverse trend with that of $\mathrm{NO}_{2}$. This could be interpreted as the chemical reaction that combination of sufficient nitrogen oxides $\left(\mathrm{NO}\right.$ and $\left.\mathrm{NO}_{2}\right)$ and total volatile organic compounds (TVOCs) could generate $\mathrm{O}_{3}$ through a series of chemical reactions under strong solar radiation, which is usually at around 3:00 pm in the afternoon.

Besides, comparison of figure 1(a), 1(c) and 1(d) shows that concentrations of $\mathrm{NO}_{2}$ and $\mathrm{CO}$ are consistent with the observation of traffic state indexes throughout the day. This is consistent with the fact mentioned above that traffic-related emissions mainly include $\mathrm{CO}$, $\mathrm{NO}_{\mathrm{x}}, \mathrm{PM}_{2.5}$ and so on. Conversely, figure 1(f) and 1(e) show that traffic state indexes have no obvious correlation with concentrations of $\mathrm{O}_{3}\left(\right.$ or $\left.\mathrm{SO}_{2}\right)$ in diurnal variation.

\subsection{Correlation between monthly air pollution concentrations and TSI}

Table 1. Spearman correlation coefficient between changes in monthly air pollution concentrations and TSI in Shanghai.

\begin{tabular}{|c|c|c|c|c|c|c|}
\hline No. & year \& month & $\mathrm{PM}_{2.5}$ & $\mathrm{O}_{3}$ & $\mathrm{SO}_{2}$ & $\mathrm{NO}_{2}$ & $\mathrm{CO}$ \\
\hline 1 & $2014 \mathrm{Aug}$ & -0.017 & $0.288^{* *}$ & $0.080^{*}$ & $0.222^{* *}$ & $0.143^{* *}$ \\
\hline 2 & $2014 \mathrm{Sep}$ & $0.110^{* *}$ & $0.237^{* *}$ & 0.015 & $0.210^{* *}$ & $0.241^{* *}$ \\
\hline 3 & $2014 \mathrm{Oct}$ & -0.028 & $0.299^{* *}$ & $0.166^{* *}$ & $-0.089^{*}$ & $0.198^{* *}$ \\
\hline 4 & $2014 \mathrm{Nov}$ & 0.036 & $0.307^{* *}$ & $0.147^{* *}$ & 0.053 & $0.110^{* *}$ \\
\hline 5 & $2014 \mathrm{Dec}$ & -0.055 & $0.385^{* *}$ & 0.055 & $-0.073^{*}$ & -0.059 \\
\hline 6 & $2015 \mathrm{Jan}$ & 0.002 & $0.163^{* *}$ & 0.067 & $0.095^{* *}$ & 0.058 \\
\hline 7 & $2015 \mathrm{Feb}$ & $0.112^{* *}$ & $0.103^{* *}$ & $0.309^{* *}$ & $0.291^{* *}$ & $0.184^{* *}$ \\
\hline 8 & $2015 \mathrm{Mar}$ & 0.070 & $0.261^{* *}$ & $0.134^{* *}$ & $0.115^{* *}$ & $0.100^{* *}$ \\
\hline 9 & $2015 \mathrm{Apr}$ & 0.020 & $0.392^{* *}$ & $0.129^{* *}$ & 0.009 & 0.001 \\
\hline
\end{tabular}

Table 1 shows the Spearman correlation coefficient between changes in monthly TSI and air pollution concentrations in Shanghai. Here, * means $\mathrm{P}<0.05$, and ** means $\mathrm{P}<0.01$. We can find the $\mathrm{O}_{3}$ concentration is positively correlated with TSI in all months, and the concentrations of $\mathrm{SO}_{2}, \mathrm{NO}_{2}, \mathrm{CO}$ are positively correlated with TSI in most months, while the correlation between $\mathrm{PM}_{2.5}$ concentrations and TSI is not obvious enough.

The relationship between $\mathrm{PM}_{2.5}$ concentrations and other air pollution concentrations are calculated by Spearman correlation in table 2. This table shows that there is a strong positive correlation in monthly concentrations between $\mathrm{PM}_{2.5}$ and other air pollutions (not including $\mathrm{O}_{3}$ ). We also find that the $\mathrm{PM}_{2.5}$ concentration is positively correlated with $\mathrm{O}_{3}$ in summer (2014 Aug \& Sep), but negatively correlated in other seasons.

This study indicates that $\mathrm{SO}_{2}, \mathrm{NO}_{2}, \mathrm{CO}$ are the dominant factors contributing to $\mathrm{PM}_{2.5}$ pollution, where $\mathrm{NO}_{2}$ and $\mathrm{CO}$ are mainly from road traffic emissions, and $\mathrm{SO}_{2}$ is mainly 
from coal combustion emissions. More studies need to be conducted to find contributions of other factors in $\mathrm{PM}_{2.5}$ pollution, such as meteorological conditions and secondary aerosol.

Table 2. Spearman correlation coefficient between changes in monthly $\mathrm{PM}_{2.5}$ concentrations and other air pollution concentrations in Shanghai.

\begin{tabular}{|c|c|c|c|c|c|}
\hline No. & year\& month & $\mathrm{O}_{3}$ & $\mathrm{SO}_{2}$ & $\mathrm{NO}_{2}$ & $\mathrm{CO}$ \\
\hline 1 & $2014 \mathrm{Aug}$ & $0.259^{* *}$ & $0.664^{* *}$ & $0.386^{* *}$ & $0.638^{* *}$ \\
\hline 2 & $2014 \mathrm{Sep}$ & $0.157^{* *}$ & $0.606^{* *}$ & $0.503^{* *}$ & $0.783^{* *}$ \\
\hline 3 & $2014 \mathrm{Oct}$ & $-0.104^{* *}$ & $0.570^{* *}$ & $0.536^{* *}$ & $0.757^{* *}$ \\
\hline 4 & $2014 \mathrm{Nov}$ & $-0.209^{* *}$ & $0.674^{* *}$ & $0.483^{* *}$ & $0.778^{* *}$ \\
\hline 5 & $2014 \mathrm{Dec}$ & $-0.478^{* *}$ & $0.776^{* *}$ & $0.649^{* *}$ & $0.872^{* *}$ \\
\hline 6 & $2015 \mathrm{Jan}$ & $-0.423^{* *}$ & $0.810^{* *}$ & $0.735^{* *}$ & $0.927^{* *}$ \\
\hline 7 & $2015 \mathrm{Feb}$ & $-0.246^{* *}$ & $0.645^{* *}$ & $0.527^{* *}$ & $0.919^{* *}$ \\
\hline 8 & $2015 \mathrm{Mar}$ & $-0.148^{* *}$ & $0.678^{* *}$ & $0.619^{* *}$ & $0.858^{* *}$ \\
\hline 9 & $2015 \mathrm{Apr}$ & $-0.237^{* *}$ & $0.778^{* *}$ & $0.645^{* *}$ & $0.776^{* *}$ \\
\hline
\end{tabular}

\section{Conclusion}

This study analyzes air pollution concentration data and traffic state indexes from August 2014 to April 2015 in Shanghai, China. We describe the seasonal, weekly and diurnal variation of air pollution and TSI in Shanghai, respectively. After that we calculate the correlation between them. Experimental results show that $\mathrm{SO}_{2}, \mathrm{NO}_{2}$ and $\mathrm{CO}$ are the dominant factors causing $\mathrm{PM}_{2.5}$ pollution, where $\mathrm{NO}_{2}$ and $\mathrm{CO}$ are mainly from road traffic emissions, and $\mathrm{SO}_{2}$ is mainly from coal combustion emissions.

\section{References}

1. Kelly F J, Zhu T. Transport solutions for cleaner air[J]. Science. 2016, 352 (6288): 934-936.

2. Zhang Y L, Cao F. Fine particulate matter $\left(\mathrm{PM}_{2.5}\right)$ in China at a city level[J]. Sci Rep, 2015, 5:14884.

3. Han L, Zhou W, Li W. Fine particulate $\left(\mathrm{PM}_{2.5}\right)$ dynamics during rapid urbanization in Beijing, 1973-2013[J]. Scientific reports. 2016, 6: 23604

4. Kendrick C M, Koonce P, George L A. Diurnal and seasonal variations of $\mathrm{NO}, \mathrm{NO}_{2}$ and $\mathrm{PM}_{2.5}$ mass as a function of traffic volumes alongside an urban arterial[J]. Atmospheric Environment. 2015, 122: 133-141.

5. Zhang Y. Analysis of Traffic Congestion based on Shanghai Road Traffic State Index[J]. Traffic \& Transportation, 2017.

6. Kulshrestha A, Satsangi P G, Masih J, et al. Metal concentration of $\mathrm{PM}_{2.5}$ and $\mathrm{PM}_{10}$ particles and seasonal variations in urban and rural environment of Agra, India[J]. Science of the Total Environment, 2009, 407(24): 6196-6204.

7. Li M, Huang X, Zhu L, et al. Analysis of the transport pathways and potential sources of $\mathrm{PM}_{10}$ in Shanghai based on three methods[J]. Science of the Total Environment, 2012, 414: 525-534.

8. Pérez P, Trier A, Reyes J. Prediction of $\mathrm{PM}_{2.5}$ concentrations several hours in advance using neural networks in Santiago, Chile[J]. Atmospheric Environment, 2000, 34(8): 1189-1196. 